\title{
Avansert blodstrømsavbildning: Vector flow imaging
}

\section{Annichen Søyland Daae}

Institutt for sirkulasjon og bildediagnostikk, NTNU og Klinikk for hjertemedisin, St. Olavs hospital, Trondheim, Norge

Siden introduksjonen av farge-Doppler teknologien på 1980-tallet [1] har vi hatt muligheten til å se blodstrømmen intrakardielt i sanntid. Dopplerteknologien er et fantastisk verktøy som har gitt oss en rekke verktøy for å forstå hjertets funksjon bedre, og gitt oss muligheten til å vurdere sykdom.

De siste årene har vi sett en rask utvikling av metoder som kan fremstille blodstrømmen intrakardielt mer nøyaktig enn det som er mulig med vanlig farge-Doppler. Vector flow imaging (VFI) er en samlebetegnelse på metoder som brukes til å fremstille den komplekse blodstrømmen i hjertet og blodårer (for spesielt interesserte kan oversiktsartiklene til Jensen et al. anbefales [2, 3]). Med VFI kan vi fremstille de komplekse

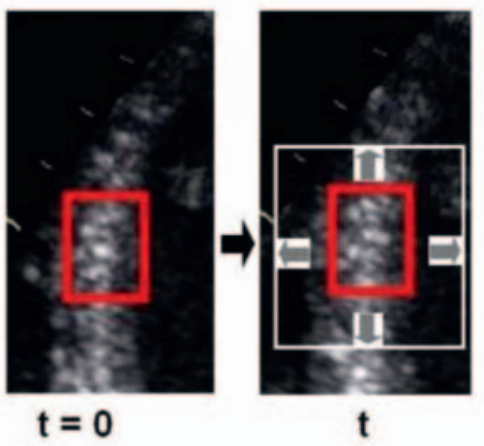

- Fig. 1 Algoritmen ved speckle tracking: Et område defineres i et tidspunkt i ultralydbildet. I neste tidspunkt søker algoritmen i et søkeområde etter et område som passer med det originale området. Slik ser med forflytning mellom ulike tidspunkt. (fra: http://folk.ntnu.no/stoylen/strainrate). blodstrømsmønstrene i intrakardielt, slik at normal og unormal vortexdannelse kan studeres. En vortex er en sirkulær eller elliptisk roterende masse av væske som spinner rundt et virtuelt senter. Rollen til en vortex i normal hjertefunksjon er å hindre kollisjon av blodstrøm, bevare et moment og bevegelsesenergi (kinetisk energi) og dermed unngå overflødig energitap. Det forskes i dag på ulike parametere knyttet til vortexdannelse intrakardielt, blant annet størrelse, utbredelse, energitap, kinetisk energi og vortisitet. Hypotesen er at unormal vortexdannelse i ventriklene kan være en indikator på sykdom som viser seg tidligere enn konvensjonelle ekkokardiografiske funksjonsparametere.

Utviklingen av ultra-rask ultralyd, også kalt ultra-high frame rate (UHFR), gir oss en så god tidsoppløsning at vi kan bruke speckle tracking ( $\triangleright$ Fig. 1), en teknologi som til nå har vært brukt til å følge myokardbevegelser, til å følge blodstrømmen intraventrikulært. På NTNU i Trondheim er metoden Blood Speckle Tracking (BST) utviklet, og denne metoden brukes i forskning både på barn [4-6] og voksne [7]. Her benyttes speckle tracking av blodet intraventrikulært, uten kontrast. De beregnede hastighetsfeltene kan brukes til å trekke ut kvantitativ informasjon om blodets hastighet og retning, som ikke er avhengig av Dopplervinkelen slik som i konvensjonelle Dopplermetoder. GE Vingmed har implementert en versjon av BST som de kaller Blood Speckle Imaging (BSI) til bruk på pediatriske prober og øsofagusproben for å fremstille blodstrømmen visuelt.

Vi har nylig publisert resultater fra en normalstudie på voksne, friske frivillige med denne metoden [8]. Fra denne studien har vi fått en større innsikt i hvor avansert blodstrømmen intraventrikulært egentlig er, og hvordan veggbevegelser og blodstrøm henger sammen i et friskt hjerte, siden geometrien av venstre ventrikkel og bevegelsen av AV-planet er viktig for vortexdannelsen. ( $\triangleright$ Fig. 2). Intrakardial blodstrøm ser ut til å starte under den isovolumetriske relaksasjonen med en propagasjon av blod fra basis til apex i ventrikkelen. Når E-bølgen starter ser vi en rask innstrømming, og vortexdannelse

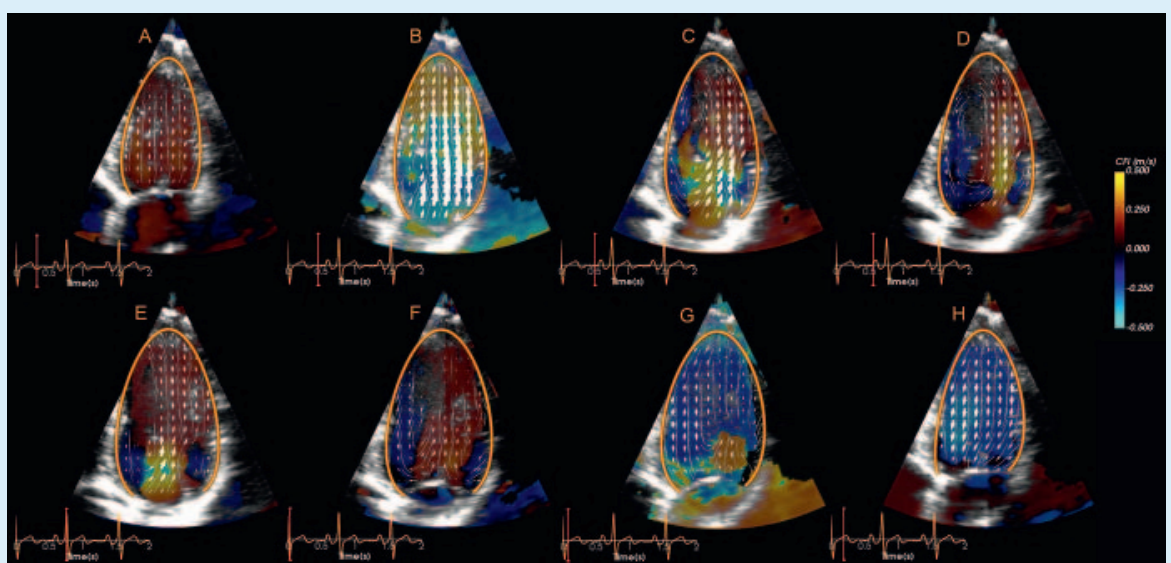

- Fig. 2 Intraventrikulær blodstrøm og vortexdannelse med Blood Speckle Tracking: Stillbilder fra åtte tidspunkt I hjertesyklusen som viser de mest tydelige blodstrøm- og vortexmønstrene i de gitte fasene. $\mathrm{A}=$ isovolumetrisk relaksasjon. $\mathrm{B}=$ Tidlig $\mathrm{E}$-bølge. $\mathrm{C}=$ Sen $\mathrm{E}$-bølge. $\mathrm{D}=$ Diastase. $\mathrm{E}=\mathrm{A}$-bølgen. $\mathrm{F}=$ Isovolumetrisk kontraksjon. $\mathrm{G}=$ Tidlig systole. $\mathrm{H}=$ Sen systole. 


\section{SAVE}

THE DATE

\section{Felles- og parallelle sesjoner}

Muskelskjelett/idrettsmedisin

Indremedisin/radiologi

- Akutt-og allmennmedisin

Obstetrikk og gynekologi

\title{
Ultralydsymposium
}

\author{
27. - 29. april 2022
}

Thon Hotel Storo, Oslo

Demonstrasjoner og praktisk trening. Frie foredrag med priser.

Festmiddag, mingling og nettverksbygging. på begge sider av mitralklaffen basalt. Under diastasen samler blodstrømmen seg i en stor vortex, før mønsteret fra E-bølgen gjentar seg under A-bølgen. Under isovolumetrisk kontraksjon samler blodstrømmen seg igjen i en stor vortex som ser ut til å legge til rette for blodstrøm ut gjennom aortaklaffen i systolen. Vi holder nå på å gjøre opp et pasientmateriale der samme metode er benyttet, og det vil bli spennende å se om denne metoden kan gi oss ny innsikt i blodstrømmen og vortexdannelsen hos pasienter med hjertesvikt og endret geometri på venstre ventrikkel.

\section{References}

[1] Omoto R, Yokote $Y$, Takamoto S et al. The development of real-time two-dimensional Doppler echocardiography and its clinical significance in acquired valvular diseases. With special reference to the evaluation of valvular regurgitation. Jpn Heart J 1984; 25: 325-340

[2] Jensen JA, Nikolov SI, Yu AC et al. Ultrasound Vector Flow Imaging-Part I: Sequential Systems. IEEE Trans Ultrason Ferroelectr Freq Control 2016; 63: 1704-1721

[3] Jensen JA, Nikolov SI, Yu AC et al. Ultrasound Vector Flow Imaging-Part II: Parallel Systems. IEEE Trans Ultrason Ferroelectr Freq Control 2016; 63: 1722-1732

[4] Nyrnes SA, Fadnes S, Wigen MS et al. Blood Speckle-Tracking Based on High-Frame Rate Ultrasound Imaging in Pediatric Cardiology. J Am Soc Echocardiogr 2020; 33: 493-503.e5
[5] Fadnes S, Wigen MS, Nyrnes SA et al. In Vivo Intracardiac Vector Flow Imaging Using Phased Array Transducers for Pediatric Cardiology. IEEE Trans Ultrason Ferroelectr Freq Control 2017; 64: 1318-1326

[6] Fadnes S, Nyrnes SA, Torp H et al. Shunt flow evaluation in congenital heart disease based on two-dimensional speckle tracking. Ultrasound in medicine \& biology 2014; 40: 2379-2391

[7] Wigen MS, Fadnes S, Rodriguez-Molares A et al. 4D Intracardiac Ultrasound Vector Flow Imaging - Feasibility and Comparison to Phase - Contrast MRI. IEEE Trans Med Imaging 2018. doi:10.1109/ TMI.2018.2844552

[8] Daae AS, Wigen MS, Fadnes S et al. Intraventricular Vector Flow Imaging with Blood Speckle Tracking in Adults: Feasibility, Normal Physiology and Mechanisms in Healthy Volunteers. Ultrasound in medicine \& biology 2021. doi:10.1016/ j.ultrasmedbio.2021.08.021 